\title{
Epidemiology of Inflammatory Bowel Disease in India: The Great Shift East
}

\author{
Saurabh Kedia Vineet Ahuja \\ Department of Gastroenterology and Human Nutrition, All India Institute of Medical Sciences, New Delhi, India
}

\section{Keywords}

Ulcerative colitis · Crohn disease · Colorectal cancer .

Pregnancy · Genetics

\section{Abstract}

Background: Inflammatory bowel disease (IBD), once considered to be a Western disease, is increasingly being reported from India and other Asian countries. The present review summarizes epidemiology and disease characteristics of IBD in India with reference to other Asian countries and the West. Summary: India is projected to have one of the highest disease burden of IBD across the globe. The overall genetic risk and microbial signature in Indian IBD patients are similar to those of patients in the West as demonstrated by the similar incidence of IBD in second-generation Indian immigrants and matching perturbations in the structural and functional component of gut microbiota in Indian studies. The concept of the hygiene hypothesis continues to remain controversial with Indian studies demonstrating contradictory findings. The disease characteristics, long-term outcomes including the risk of colorectal cancer, and the effect of pregnancy on IBD and vice versa in Indian patients with IBD are in general similar with few differences. Unlike patients in the West, very few Indian patients have a positive family history. Key Mes- sage: The Indian disease pattern is going through a phase of epidemiological transition with a surge in the incidence of IBD. The epidemiology and disease characteristics of IBD mirror the patterns observed in the West.

(c) 2017 S. Karger AG, Basel

\section{Introduction}

Inflammatory bowel disease (IBD) has been considered as a disease of white people of European descent living in industrialized regions of the Western world. In South Asia and South East Asia, occasional case series of ulcerative colitis (UC) would surface; however, Crohn disease (CD) has distinctly been considered a rare entity [1]. Yet over the last two decades, India appears to be on the epidemiological crossroads where infectious diseases as well as diseases hitherto considered to be diseases of the Western world are both being witnessed. Although the

Contribution from the American Gastroenterological Association (AGA) International Committee-sponsored symposium "Inflammatory Bowel Disease: Is It Different between East and West?" held during the Digestive Disease Week 2016 in San Diego, CA, USA, on May $22,2016$.

\section{KARGER}

(C) 2017 S. Karger AG, Basel 
Table 1. Comparison of incidence IBD among Asian countries and India

\begin{tabular}{llll}
\hline Location & IBD & UC & CD \\
\hline $\begin{array}{lll}\text { Mainland China } \\
\quad \text { Chengdu }\end{array} \quad 0.56$ & 0.15 & 0.42 \\
$\quad$ Guangzhou & 3.14 & 1.09 & 2.06 \\
$\quad$ Xian & 0.5 & 0.05 & 0.4 \\
Hong Kong & 2.62 & 1.25 & 1.30 \\
Indonesia & 0.83 & 0.27 & 0.56 \\
Malaysia & 1.01 & 0.18 & 0.71 \\
Singapore & 0.97 & 0.39 & 0.51 \\
India & & 6.02 & \\
\hline
\end{tabular}

Values are given as $n / 100,000$ people.

IBD, inflammatory bowel disease; UC, ulcerative colitis; CD, Crohn disease.

rarity of IBD in India has been questioned more than 50 years back, a lack of good epidemiological studies could not reconfirm this astute observation [2]. The study of IBD epidemiology in these regions has been hampered by several factors including a lack of universal accessibility to health care, hospital-based studies, the absence of standardized case definitions, relevant databases, and registries with appropriate validation, and prospective data collection. Hospital-based studies are easy to conduct but are likely to underestimate the incidence and overestimate the disease severity of these so-called "rare" diseases.

\section{Epidemiology of IBD in India}

\section{Disease Burden of UC and CD in India}

There are two population-based studies which have looked into the burden of UC in India. The first such study was conducted by Khosla et al. [3] in 1984 in Haryana in North India. The study included 21,971 participants and noted a prevalence of $42.8 \mathrm{UC}$ patients per 100,000 people. The second study, conducted 15 years later by Sood et al. [4] from Punjab (this state neighbours Haryana), employed a cluster sampling method and calculated age-standardized prevalence rates after screening a population of 51,910 people of which two thirds lived in rural parts of Punjab and the rest in urban parts. Overall, 23 patients were diagnosed with UC leading to a prevalence rate of $44.3 / 100,000$. The incidence was calculated again during a second visit to the same area 1 year later and was reported to be $6.02 / 100,000$. These data again indicate that UC is not rare in India. However, these find-

Epidemiology of IBD in India ings go against the general belief that the burden of IBD is on the rise in Asian countries, especially when data from other regions suggest so. A comparison of incidence and prevalence rates with other countries suggests that among Asian countries the disease burden is highest in India. A recent epidemiological study, entitled "The AsiaPacific Crohn's and Colitis Epidemiologic Study (ACCESS)" by Ng et al. [5] who studied incident IBD cases diagnosed between April 2011 and March 2012, reported the incidence and prevalence of IBD from 8 Asian regions and Australia (Table 1). The crude overall incidence of IBD, UC, and CD from Asia was 1.37, 0.76, and 0.54 per 100,000, respectively, whereas in Australia it was 23.67, 7.33 , and 14.00, respectively. Among the Asian countries, it was highest in mainland China (Guangzhou: 3.4/ $100,000)$ followed by Hong Kong $(3.06 / 100,000)$, and Macau (2.2/100,000). Data from Western Asia including studies from Kuwait [6], Turkey [7], and Israel [8] revealed an incidence rate of 2.8/100,000 and 5.04/100,000 in Kuwait and Israel, respectively, and a prevalence of $4.9 / 100,000$ and 167/100,000 in Turkey and Israel, respectively.

There are no population-based studies to determine the incidence and prevalence of CD; and CD burden can only be estimated indirectly from hospital-based cohort studies. A multicentre study from northern and eastern regions of India indicated that there was a cumulative rise in the number of patients with CD from fewer than 5,000 in 1987 to 21,061 in 2001, giving an indirect estimate of disease burden and its rise over the years in India [9]. The incidence of CD from other Asian countries, as reported in the ACCESS study, varies from $0.05 / 100,000$ (mainland China [Xian]) to $1.25 / 100,000$ (Hong Kong) [5].

\section{UC versus CD Burden: Developed and Developing Countries}

It is believed that the burden of UC is twice that of $\mathrm{CD}$ in Asia as compared to the West [10-12]. In the ACCESS study, the incidence and prevalence of UC was twice that of $\mathrm{CD}$ in the included Asian countries, whereas in Australia a reverse ratio was observed [5]. The incidence and prevalence of IBD mirrors the Western experience that occurred 50 years ago [13-15]. Epidemiological studies from Western countries have shown that the increase in the incidence of UC preceded the increase in that of CD by about 15-20 years [16]. The rise in UC appeared to be more marked compared to the rise in CD. However, as the disease burden in the West has plateaued $[17,18]$, the UC/CD gap has decreased and even reversed as indicated in the ACCESS study. The same is being observed in Asia

Inflamm Intest Dis 2017;2:102-115 
Fig. 1. Estimated disease burden of IBD in 6 countries from Asia, North America, or Europe calculated for reference year 2010.

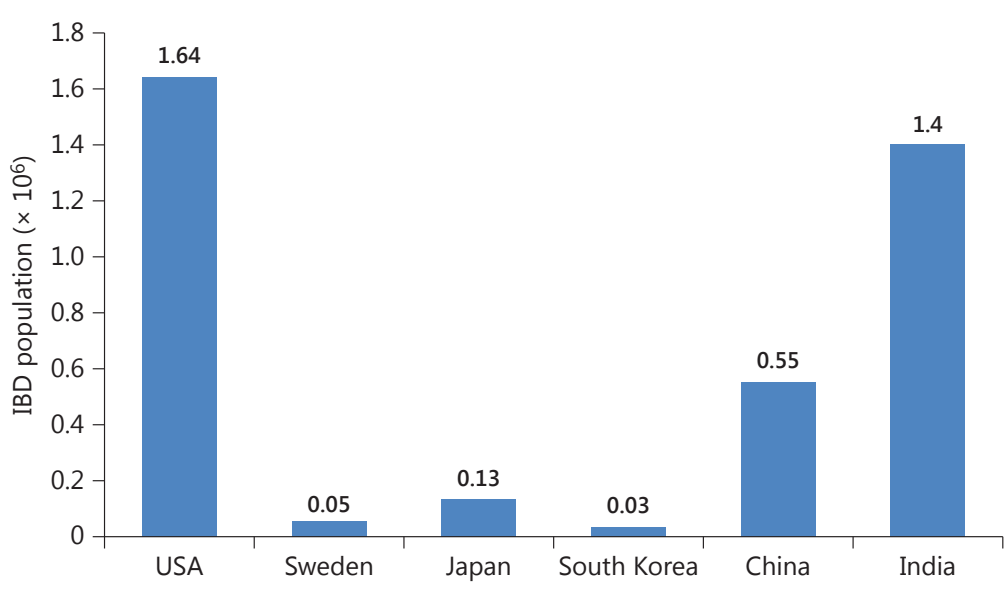

as well with the UC/CD ratio narrowing in Hong Kong $[19,20]$. With increasing disease burden, India could also observe such a shift in the UC/CD prevalence.

\section{North-South Gradient}

The IBD epidemiology in India does not follow the North-South divide as observed in studies from the USA and Europe, where the IBD burden is much higher in the North as compared to the South $[1,21,22]$. The IBD survey published in 2012 revealed that IBD was seen in all parts of North and South India [23]. Different exposure to sunlight and hence to vitamin D (which has an antiinflammatory and immunomodulatory role) may account for such a North-South gradient in the West [24]. India being a tropical country may not follow this NorthSouth gradient in terms of sunlight exposure. The exact reason why $\mathrm{CD}$ is more commonly seen in Southern India as compared to Northern India is not clear.

\section{Increasing Disease Burden of IBD}

There is a general trend which has emerged from the epidemiological studies conducted across Asia and worldwide. It is apparent from these studies that the disease burden of IBD is on the rise in Asian countries and is mimicking the rise which was observed in American and European countries in the last decade [25]. Also the number of publications on IBD has markedly increased from these regions, again indicating the rise in disease burden and increasing interest in IBD among researchers from these regions. Although the 2 serial studies from India indicated that the disease prevalence of UC remained similar from 1984 to 2009 [3, 4], studies from other Asian countries indicate that the disease burden of IBD is on the rise. The prevalence of CD in Japan appears to have risen rapidly from $2.9 / 100,000$ individuals in 1986 to $13.5 /$ 100,000 individuals in 1998 [12]. In South Korea, the prevalence for UC quadrupled from 7.57/100,000 individuals in 1997 to $30.87 / 100,000$ individuals in 2005 [26]. Over a period of 9 years, the prevalence of UC in Hong Kong nearly tripled from $2.26 / 100,000$ individuals in 1997 to $6.30 / 100,000$ individuals in 2006 [19]. Similarly, CD prevalence in Singapore also increased markedly from 1.3/100,000 individuals in 1990 to $7.2 / 100,000$ individuals in 2004 [27].

In another migrant epidemiological study, Tsironi et al. [28] compared the incidence of IBD and abdominal tuberculosis (TB) in immigrants originating from Bangladesh and found that over a period of 10 years the incidence of IBD had more than tripled, whereas over the same time period the incidence of abdominal TB had reduced to less than half. In addition to increased awareness among physicians and improved diagnostic techniques, the major thrust behind the increasing disease burden of IBD in Asia would be the actual increase in the IBD population, and this could be the result of urbanization along with changes in dietary patterns and better hygienic conditions.

\section{Estimated Disease Burden of IBD in India}

We have recently compared the overall disease burden between the West and the East [29], and came to the staggering observation that the overall disease burden (when both prevalence and population were taken into account) was among the highest in India (Fig. 1). The present re- 


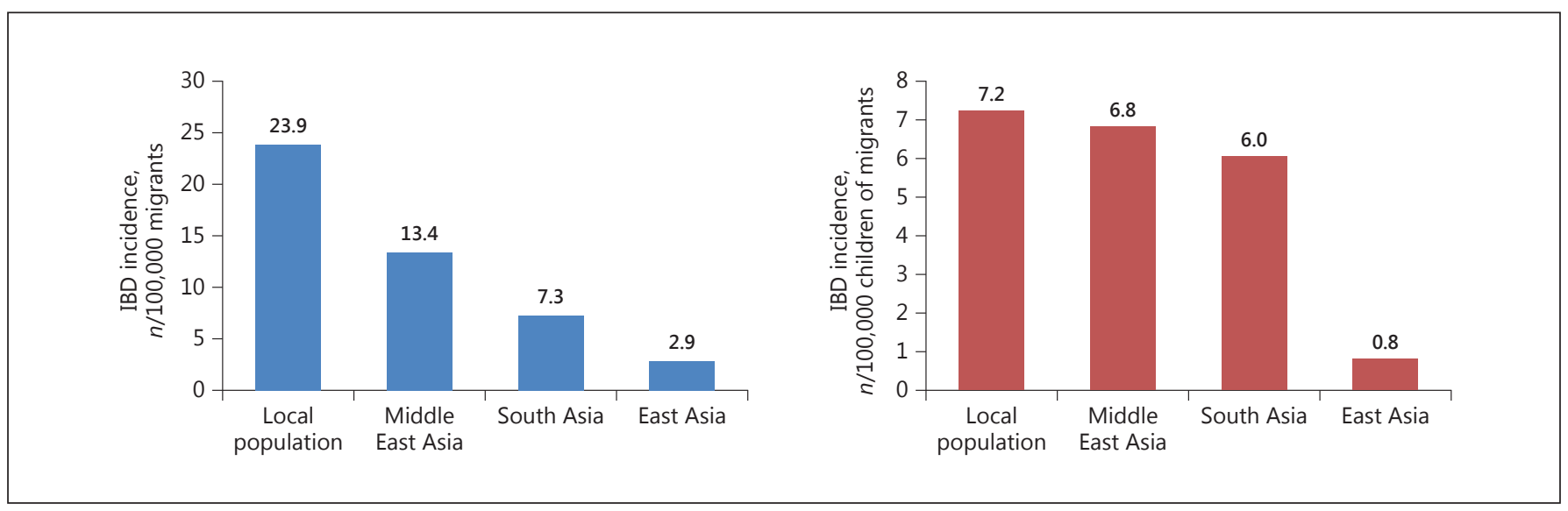

Fig. 2. Comparison of the incidence of ulcerative colitis in Asian immigrants and the local population in Ontario, Canada.

view employed figures from one geographical area as representative of the entire country, and CD disease burden (where not available) was taken as one third of UC prevalence. The overall estimated IBD population in India in 2010 came out to be 1.4 million, which was the second highest number after the USA (with 1.64 million). Therefore, although the disease prevalence in India is lower than in the West, with a population of more than 120 million, the total IBD population in India is among the largest across the globe.

\section{Migrant Epidemiology}

Studies on Asian migrants in the West provide another opportunity for studying the interaction of different genetic (Asian) and environmental (Western) factors in the pathogenesis of IBD. The epidemiology of disease in these populations, who have moved from a low-incidence area to a high-incidence area, can generate information related to the evaluation of environmental aetiologies for disease development. A retrospective epidemiological study conducted in the early 1990s indicated that the standardized incidence of UC in South Asians residing in Leicestershire, UK, was significantly higher than that of the local population $(10.8 / 100,000$ vs. $5.3 / 100,000)$, and among the South Asians the incidence was highest in Sikhs $(16.5 / 100,000)$ followed by Hindus $(10.8 / 100,000)$ [30]. However, the same group found that although the incidence of CD had increased over time in both Europeans and South Asians, the incidence was significantly lower in South Asians as compared to Europeans [31]. In another migrant study, Benchimol et al. [32] compared the incidence of IBD among immigrants and non-immi-

Epidemiology of IBD in India grants of Ontario, Canada, and found that the incidence of IBD among the immigrants was significantly lower that of the resident population (7.3/100,000 vs. 23.9/100,000). However, the incidence of IBD among the children of these immigrants was significantly higher than that of their parents and approached that of non-immigrants (Fig. 2). These findings may indicate that the early-life exposure to the environment of high-incidence areas could be a determining factor in pre-disposing these patients to develop IBD.

\section{Risk Factors for Disease}

\section{Genetics}

The genetic architecture in IBD reflects polymorphisms in genes that are usually associated with the crosstalk between the commensal microbiota and gut immune system. Until today, more than 200 such IBD-specific genetic loci have been identified through genome-wide association studies (GWAS) across the globe. Of these, a meta-analysis which combined GWAS with immunochip data identified 163 loci, 110 of which were common to both $\mathrm{CD}$ and $\mathrm{UC}$, and 30 and 23 were specific to $\mathrm{CD}$ and UC, respectively [33]. These loci could explain 13.6 and $7.5 \%$ of the total disease variance of UC and CD, respectively. Thirty-eight additional loci have been identified recently by Liu et al. [34] in a trans-ethnic analysis. The initial data for the GWAS originated primarily from Europe, but off late there have been many such publications from Asia, including Japan, Korea, and India. These studies demonstrate both similarities and dis-similarities in 
the genetic architecture of Caucasians and non-Caucasians. Of these genetic loci, the genetic polymorphism NOD2 has the strongest association with IBD, especially $\mathrm{CD}$. However, recent studies which assessed the NOD2 polymorphisms in Indians could not find such an association, and 3 common CD-associated NOD2 polymorphisms were not found in Indian patients [35-37]. However, 2 of these studies could find a weak association of rs2066842 (Pro268Ser) with UC [35, 37].

In another study, Juyal et al. [38] reported the association of UC/CD-specific genetic loci (published in a metaanalysis on a European population) in a North Indian population. They studied 53 such loci and found that 25 SNPs were associated with IBD in Indians of which 15 were $\mathrm{CD}$ specific. However, only 5 SNPs, namely rs2395185 (HLA-DRA), rs3024505 (IL10), rs6426833 (RNF186), rs3763313 (BTNL2), and rs2066843 (NOD2), retained significance after Bonferroni correction. Another Indian study reported a strong protective association with TNFSF15 (tumour necrosis factor superfamily) gene polymorphisms and IBD in the Indian population [39]. TNFSF15 has also been associated with an IBD risk in studies from Japan and the UK [40, 41]. The same group also reported an association of an autophagy-related gene, the IRGM gene (which has had a positive association with $\mathrm{CD}$ in multiple European studies), with CD in the Indian population [42].

We reported polymorphisms of the NOD1 protein in UC patients [43] and found an association of 3 SNPs which led to significant mutations in ATP and $\mathrm{Mg}^{2+}$-binding domains of Exon 6 of the NOD1 gene that may cause defective oligomerization and subsequently the "loss of function" of the protein, thereby preventing the recognition of muramyl dipeptide that is necessary for a subsequent NF$\kappa \mathrm{B}$ activation [44]. In another study from our centre, we reported the association of the TLR4 D299G polymorphism with both UC and CD, and of the T399I polymorphisms only in UC [45]. These polymorphisms contribute to modulating the transcription of inflammatory cytokines in UC, leading to an aberrant immune response. In the third such study, we found that the TLR5 variants R392X and N592S showed significant association with UC [46]. We also correlated them with disease phenotype and showed that patients having a combination of multiple SNPs both in the TLR5 and the TLR4 gene suffered from early-onset disease which had a severe long-term course.

Mahurkar et al. [36] reported that in addition to NOD2, the protective allele of the Il23 gene (R381Q) was not associated with CD in the Indian population. Few Indian studies have also correlated genes with phenotype of
IBD in India. MDR1 (ABC B1) gene polymorphisms were associated with early age at disease onset, left-sided disease, and steroid response in UC [47]. In another study, the IL4 B2 carrier state was less frequently expressed in left-sided colitis as compared to proctosigmoiditis and was absent in colonic CD [48]. A recent GWAS on UC in a North Indian population revealed 3 novel HLA-independent loci as susceptibility genes located in 3.81, BAT2, MSH5, HSPA1L, SLC44A4, CFB, and NOTCH4 [49]. Studies from Japan $[50,51]$ have also confirmed the absence of NOD2 polymorphisms in Asians, and in addition, there was no association with another autophagyrelated gene, ATG16L1, in the Asian populations. A trans-ethnic study which included East Asians, Indians, Iranians, and Caucasians identified 38 novel disease susceptibility loci [34]. The study demonstrated a shared genetic risk across different populations along with genetic heterogeneity with NOD2 polymorphisms being absent in Asians and TNFSF15 having a much larger effect size in Asians as compared to Caucasians.

\section{Microbiome}

IBD is probably the result of an abnormal immune response to intestinal microbiota in genetically susceptible individuals [52]. Gut microbiome studies in IBD patients have demonstrated a reduced diversity in the bacterial population, especially because of a reduced diversity within the Firmicutes phylum [53]. We studied mucosaassociated bacterial flora from control individuals and IBD patients by real-time analysis using $16 \mathrm{~S}$ rRNA-based genus-specific primers [54]. There was a significant decline in the population of Bacteroides, Lactobacillus, $R u$ minococcus, and Bifidobacterium bacteria in both UC and CD patients. Similar results have been reported in earlier studies from the West [55-57].

In contrast to the mucosal studies, we found that Lactobacilli in the faecal samples of patients with active UC are significantly increased as compared to healthy controls (unpubl. data). These levels of Lactobacilli significantly reverted back to normal during remission, and reached levels close to those of controls. This was further supported by an increase in faecal lactate level (as measured by gas chromatography) in severe UC patients as compared to controls. Our findings again replicate the results from other studies from the West $[58,59]$. In addition to differences at the phylogenetic level, there are differences in the functional composition of gut microbiota in IBD patients as compared to controls.

We also studied the interplay between butyrate concentration and butyrate-producing bacteria in faecal
106

Inflamm Intest Dis 2017;2:102-115 DOI: $10.1159 / 000465522$
Kedia/Ahuja 
Table 2. Comparison of environmental risk factors for ulcerative colitis (UC) and Crohn disease (CD) in Indian studies and the ACCESS study

\begin{tabular}{|c|c|c|c|c|}
\hline \multirow[t]{2}{*}{ Factor } & \multicolumn{2}{|l|}{ India } & \multicolumn{2}{|l|}{ ACCESS } \\
\hline & $\begin{array}{l}\mathrm{UC} \\
(n=518)\end{array}$ & $\begin{array}{l}\mathrm{CD} \\
(n=200)\end{array}$ & $\begin{array}{l}\mathrm{UC} \\
(n=186)\end{array}$ & $\begin{array}{l}\mathrm{CD} \\
(n=256)\end{array}$ \\
\hline Breast feeding $>12$ months & - & - & protective & protective \\
\hline Childhood pets & prone & no effect & protective & protective \\
\hline Antibiotic use & - & - & protective & protective \\
\hline In-house water tap & no effect & prone & protective & no effect \\
\hline Bed sharing & prone & - & - & - \\
\hline Toilet facilities & protective & no effect & protective & no effect \\
\hline Higher number of siblings & no effect & - & - & - \\
\hline Cattle in the house compound (recently) & - & protective & - & - \\
\hline
\end{tabular}

samples of UC patients and healthy individuals [60]. There was a significant decrease of Clostridium coccoides and Clostridium leptum clusters in the faecal samples of the UC patients. In addition, we could also demonstrate decreased concentrations of faecal SCFAs, especially of n-butyrate, iso-butyrate, and acetate, in the faecal samples of the UC patients. Our results support similar observations made in earlier studies [61].

Therefore, the microbiome signature in the Indian IBD population matches that of patients in the West, indicating that the players in the pathogenesis of IBD are not different between the West and the East.

\section{Smoking}

Unlike in the West where smoking has been shown as a risk factor in the development of $C D[62,63]$ and where it also negatively influences the natural history of CD, studies from Asia have not reproduced these results [64]. There was no relationship between smoking and severity of IBD in a study from China. Similarly, we also reported that there was no difference in disease phenotype of $C D$ between smokers and oral tobacco users versus nonsmokers and tobacco non-users (unpubl. data). Additionally, smoking and tobacco use did not influence the long-term outcomes of patients with CD. There was no difference in rates of surgery, and requirement of biologics, immunomodulators, and steroids between smokers, oral tobacco users, and non-smokers, and tobacco nonusers.

\section{Other Environmental Factors: The Hygiene}

Hypothesis (Table 2)

A study of $200 \mathrm{CD}$ patients from Vellore investigated the association of environmental and dietary factors with the diagnosis of $\mathrm{CD}$ [65]. On univariate analysis, a positive association was found with urban residence (at birth and current), availability of protected drinking water (childhood and current), availability of piped water in the house (childhood and current), and strict vegetarian dietary habit, and a negative association with regular fish consumption and the presence of cattle in the house compound. On multivariate analysis, only regular fish consumption and the presence of cattle in the house had a protective association, whereas the use of safe drinking water was positively associated with $\mathrm{CD}$. Another study from North India demonstrated that better toilet facilities and having a private bed were inversely associated with UC, whereas owning a pet and stressful life events were associated with a greater risk for UC [66]. In a multicentre Asian study (ACCESS), being breast fed $>12$ months, antibiotic use, and daily tea or coffee consumption were protective against both UC and CD, having dogs, and daily physical activity were protective only against $C D$, and the availability of a hot water tap and flush toilets in childhood were protective only against UC [67]. Therefore, the literature supporting the hygiene hypothesis is inconsistent both in India as well as other Asian countries, making it a concept that is not easy to measure.

\section{Disease Characteristics}

\section{Age}

IBD in the West is characterized by a bimodal age distribution with peaks at age groups 20-39 and 60-79 years. Secondly, the mean and median age at diagnosis of CD is a decade earlier than that of UC. There are several hospital-based cohort studies from India which describe the 
Fig. 3. Comparison of disease extent of ulcerative colitis among studies in India and Asia.

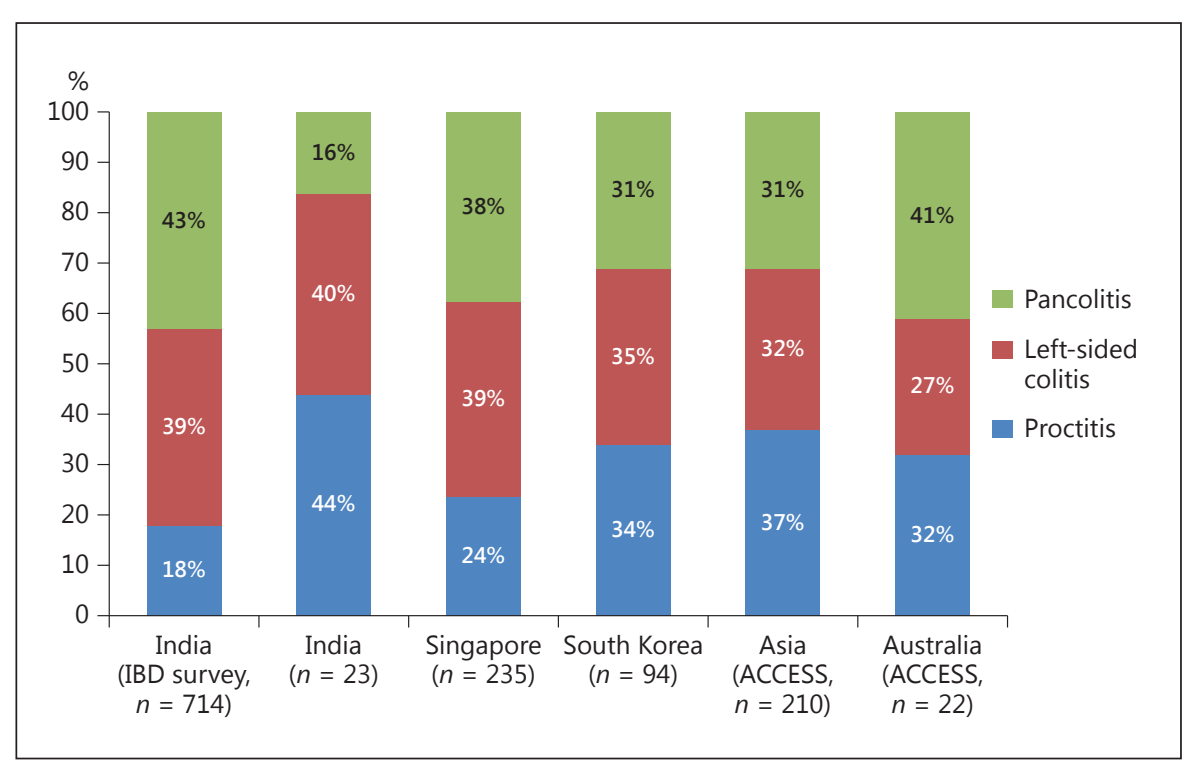

age at onset of IBD. In a country-wide survey of IBD from India, the mean age at diagnosis of UC and CD was 38.5 and 35.9 years, respectively, and was not associated with a second peak [23]. In another study from 3 centres, the mean age at onset of CD symptoms was 34.5 years without a second peak [9]. Similarly in the ACCESS study, the median age at UC and CD diagnosis was 42 and 34 years, respectively, and $\mathrm{CD}$ was associated with a second smaller peak at 40-44 years, whereas UC had a single peak [5]. Therefore, although the age at IBD onset in India is similar to that in the West and CD occurs at a younger age than UC like in the West, the bimodal peak as observed in the West is not observed in India and other Asian countries.

\section{Gender}

Data from the West indicate that the gender distribution in UC is either equal to or associated with a sight male preponderance, whereas in CD it is consistently associated with a female preponderance. All studies from India consistently indicate that, like in the West, UC is associated with a slight male preponderance; whereas, unlike in the West where females predominate, $\mathrm{CD}$ is also associated with a higher male:female ratio $(>1)$. The IBD survey reported a male:female ratio of 1.4 and 1.3 for UC and $C D$, respectively [23]. Similarly, the study on CD from 3 centres also reported a male:female ratio of 1.8 [9]. This male preponderance seen in the Indian cohort could be attributed either to a relatively low incidence as compared to the West or a representation of socio-referral bias, where women and girls are underrepresented in receiving medical attention.

\section{Disease Location and Behaviour}

Ulcerative Colitis

The data from the IBD survey indicate that out of 714 patients with UC, the disease extent was pancolitis in 306 (42.8\%) patients, left-sided colitis in 277 (38.8\%), and proctitis in $18.3 \%$ patients [23]. A similar pattern of disease extent was seen in another study from India and from other parts of Asia such as Singapore and South Korea (Fig. 3). The ACCESS study also reported similar disease locations in Asians as well as Australians with proctitis, left-sided colitis, and pancolitis been seen in 37 and $32 \%, 32$ and $27 \%$, and 31 and $41 \%$, respectively [5]. Therefore, in general the disease locations found in Indians are almost similar to those found in other Asian countries and the West.

\section{Crohn Disease}

In a multicentre study on 182 patients from 3 centres, the disease location was L1 (terminal ileal) in 32\%, L2 (colonic) in $41 \%$, L3 (ileocolonic) in 23\%, and L4 (proximal small intestinal) in $4 \%$. Perianal disease was seen in $17 \%$ of all patients [9]. Among 394 CD patients, the IBD survey also reported almost similar disease locations with $\mathrm{L} 1$ disease in $29 \%, \mathrm{~L} 2$ in $31 \%, \mathrm{~L} 3$ in $40 \%$, and L4 in $6 \%$ of all patients [23]. Two other studies from India, a study on 178 patients from Mumbai [68] and a study on 200 patients from Vellore [65], also reported similar disease lo- 
Fig. 4. Comparison of disease location (a) and disease behaviour (b) of Crohn disease among Indian studies and the ACCESS study. L1, terminal ileal; L2, colonic; L3, ileocolonic; L4, proximal small intestinal. B1, inflammatory disease; B2, structuring disease; B3, fistulizing disease.

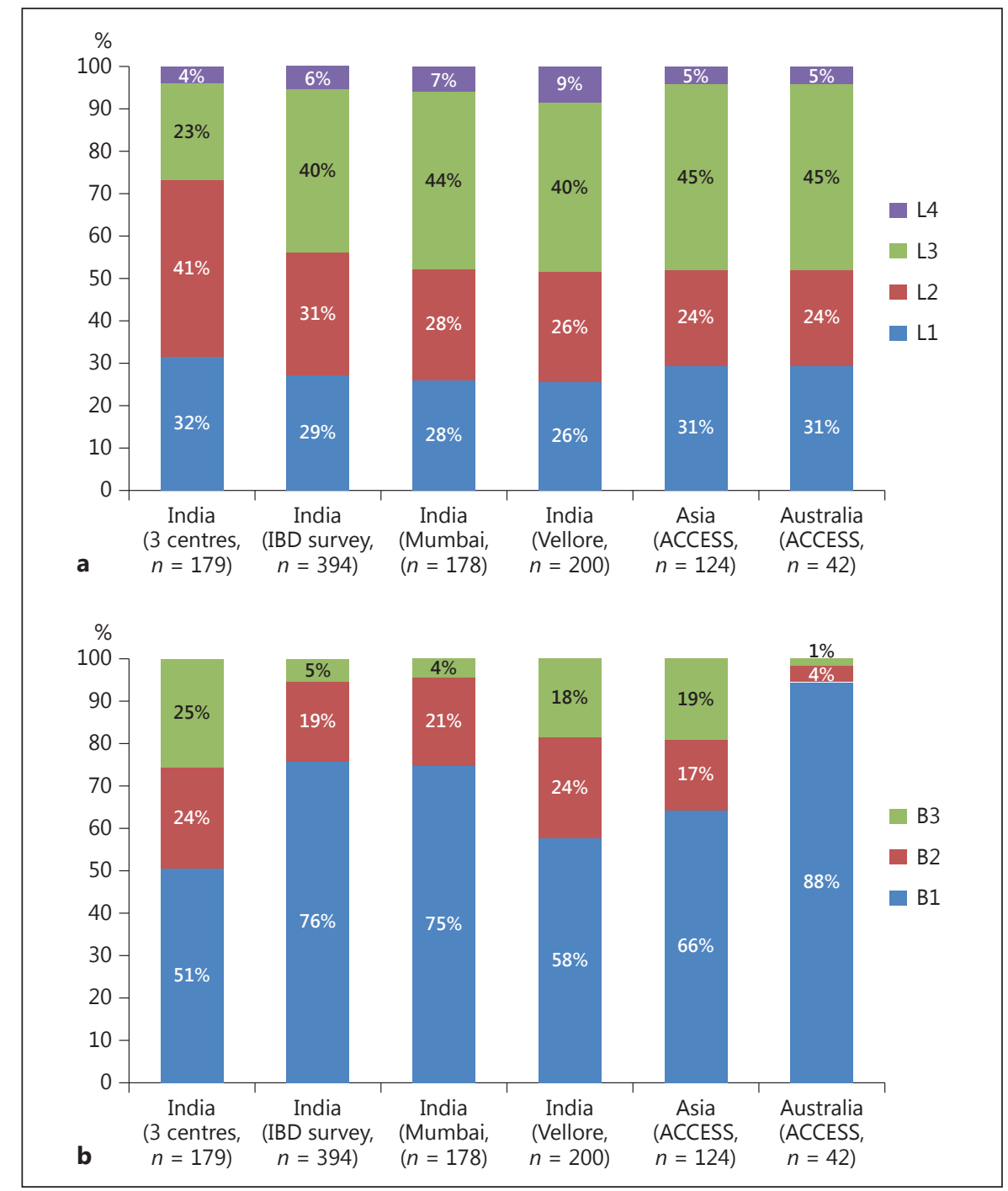

cations (Fig. 4a). The ACCESS study reported similarity in disease location between Asians and Australians, with L1, L2, L3, and L4 disease being seen in 31 and 31\%, 24 and $24 \%, 45$ and $45 \%$, and 5 and $5 \%$ of all patients, respectively [5]. Therefore, overall, L3 disease is the most common disease location across India, Asia, and the West, followed by varying distributions of L1 and L2 disease locations.

\section{Disease Behaviour in CD}

As seen in the West, inflammatory disease (B1) is the commonest disease phenotype seen in $51-76 \%$ of all patients, followed by stricturing disease (B2) and fistulizing disease (B3) which were seen in $19-25 \%$ and $4-24 \%$ of all patients, respectively (Fig. 4b). Perianal disease modifiers

Epidemiology of IBD in India were seen in $7-17 \%$ of all patients. Among these Indian studies, the disease phenotype was milder in the IBD survey, with more patients having the inflammatory phenotype $(76 \%)$ as compared to the other studies [23]. This discrepancy could be attributed to referral bias, as the other studies were from tertiary care centres. Similarly, perianal disease modifiers were also seen at a lower frequency in the IBD disease survey. The disease phenotype among the Asians in the ACCESS study also matched the Indian data from hospital-based cohorts [5]. However, the Australians had a milder disease with $88 \%$ of all patients having the inflammatory phenotype. CD is characterized by the progression of disease phenotype with time, with a transition from the inflammatory to the stricturing or the penetrating phenotype as reported in studies 
Table 3. Comparison of long-term outcome after ASUC between published studies and a recent Indian study

\begin{tabular}{|c|c|c|c|c|c|c|}
\hline Author/year & Area & $\begin{array}{l}\text { Patients with } \\
\text { ASUC, } n\end{array}$ & $\begin{array}{l}\text { Colectomy at } \\
\text { hospitalization }\end{array}$ & Median FU & $\begin{array}{l}\text { Colectomy } \\
\text { at FU }\end{array}$ & Overall \\
\hline Gustavsson et al. [72], 2007 & Sweden & 61 & $28 / 61(46 \%)$ & 173 months & $11 / 33(33.3 \%)$ & $39 / 61(64 \%)$ \\
\hline Bojic et al. [73], 2009 & Oxford & 49 & $14 / 49(28.5 \%)$ & 122 months & $16 / 32(50 \%)$ & $30 / 49(61 \%)$ \\
\hline Dinesen et al. [70], 2010 & Oxford & 186 & $37 / 186(19.9 \%)$ & 129 months & $37 / 147(25 \%)$ & $74 / 186(39.8 \%)$ \\
\hline Molnár et al. [74], 2011 & Hungary & 183 & $16 / 183(8.7 \%)$ & 4.4 years & $29 / 167(17.3 \%)$ & $45 / 183(24.6 \%)$ \\
\hline Lee et al. [75], 2015 & South Korea & 99 & $16 / 99(16.2 \%)$ & 10.6 years & $13 / 83(15.7 \%)$ & $29 / 99(29.3 \%)$ \\
\hline Jain et al. [71], 2016 & India & 179 & $19 / 179(10.6 \%)$ & 56 months & $42 / 160(26.3 \%)$ & $61 / 179(34.1 \%)$ \\
\hline
\end{tabular}

ASUC, acute severe ulcerative colitis; FU, follow-up.

from the West. Similarly, a retrospective study from Mumbai (Western India) also reported the progression to a more aggressive disease in $20 \%$ of all patients over a period of 10 years [68]. However, this progression was relatively slower when compared to that of the West, where studies have reported $31 \%$ of all patients having disease progression over the same time period.

\section{Long-Term Disease Course and Treatment}

The long-term disease course of Indian UC patients is generally similar or slightly milder than that of patients in the West. In the Leicestershire cohort, although the disease extent was similar in all ethnic groups, the South Asians had less surgery and fewer complications as compared to the Europeans. In the IBD survey [23], one third of the patients had a chronic active course, one half had a relapsing remitting course, and $4 \%$ of all patients had undergone surgery. However, information on the disease duration was not available in this study. We analyzed the data of 161 UC patients who had received steroids and found that after 1 and 3 years 44 and 66\% were in complete remission, respectively, and $10 \mathrm{pa}-$ tients $(6.2 \%)$ had undergone surgery over a period of 3 years [69]. The overall colectomy rate was $12 \%$ in the diagnosed UC cohort from Oxford, UK [70]. Therefore, these data indicate that the overall colectomy rates are lower in Indian patients as compared to patients in the West, indicating a slightly milder disease in India. Other reasons for lower colectomy rates in India could be social factors with fewer Indian patients being receptive for colectomy. In the IBD survey, approximately two thirds of all UC patients had received steroids, $30 \%$ had received azathioprine (AZA), and less than $1 \%$ of all patients had received biologics [23]. The lower use of biologics in Indians reflects the lack of affordability and in- surance cover for most of the patients. We have recently conducted a retrospective analysis of 179 patients with acute severe UC who were followed from discharge till a median of 56 months [71]. The colectomy rate at admission in our study was lower than that reported in the West, but matched the Asian data (Table 3). The longterm colectomy rate in our study was $34 \%$, which was lower than that reported by two earlier studies from Sweden (64\%) [72] and Oxford (61\%) [73], but comparable to the recent studies from Oxford (40\%) [70], Hungary (25\%) [74], and South Korea (29\%) [75]. These differences could be explained by an absence of immunomodulator use in the Swedish cohort, regional differences in the behaviour of disease (Asia vs. West), and the duration of follow-up.

Among CD patients, the study from 3 centres from India reported that $37 \%$ of all patients required surgery [9]. The medications used were 5-aminosalycylic acid (5ASA) compounds in $78 \%$ of all patients, steroids in $42 \%$ of all patients, AZA in $29 \%$ of all patients, and methotrexate in $2 \%$ of all patients. In the IBD survey, 5 -ASA was used only in $64 \%$ of all patients, steroids in $69 \%$ of all patients, the use of AZA was higher than in the previous study (63\%), and biologics were used in $2 \%$ of all patients only [23]. In the Mumbai cohort, after 15 years of followup, $55 \%$ of all patients required surgery [68].

Another important finding that is visible in the Indian studies is the use of antitubercular therapy (ATT) in 22, 37 , and $43 \%$ of all patients in the Mumbai study, IBD survey, and the triple-centre study, respectively. Intestinal TB (ITB) is a close mimic of CD, and it is often difficult to differentiate the two diseases on the basis of clinical, endoscopic, histological, and radiological characteristics. This dilemma often leads to a therapeutic ATT trial because $\mathrm{CD}$-specific therapy (i.e. steroids) can be disastrous
110

Inflamm Intest Dis 2017;2:102-115 DOI: $10.1159 / 000465522$
Kedia/Ahuja 


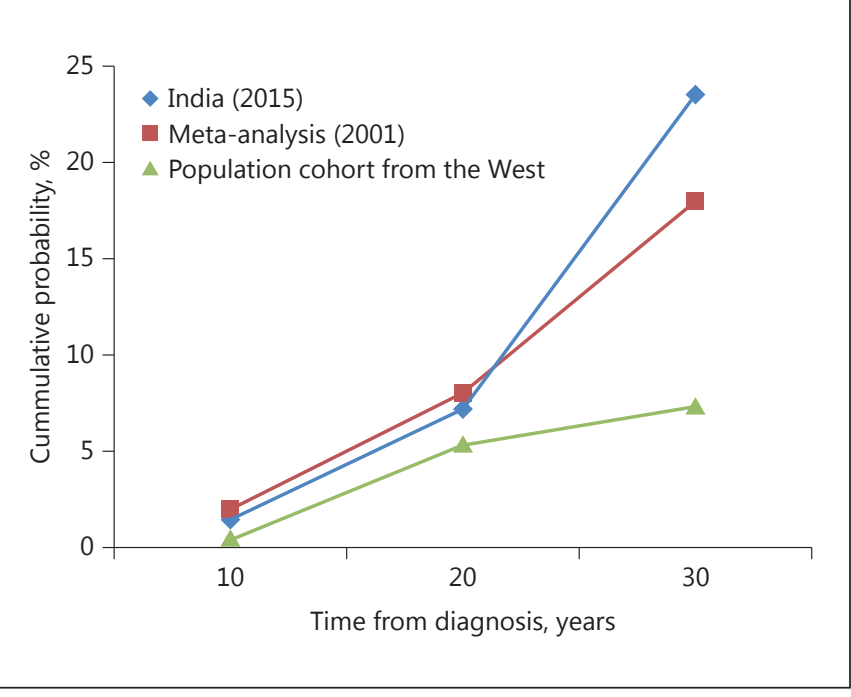

Fig. 5. Cumulative probability of colectomy after 10, 20, and 30 years in studies from India (2015), a meta-analysis (2001) [103], and a population-based cohort from the West.

if a patient has ITB. The endoscopic and clinical response to a therapeutic ATT trial can help in differentiating CD from ITB [76]. We found that although up to $38 \%$ of all patients with CD had good clinical response to 6 months of ATT, less than $5 \%$ had mucosal healing in comparison to ITB, where all patients showed clinical as well as endoscopic response. Therefore, in a patient with a diagnostic dilemma of CD and ITB after all investigations, we advocate a therapeutic ATT trial and then to follow up the patient based upon the clinical and endoscopic response to ATT.

\section{Extra-Intestinal Manifestations}

Except for the study by Pokharna et al. [77] which reported a lower prevalence of extra-intestinal manifestations (EIMs) in Indian patients as compared to those from the West, other studies indicate that the overall prevalence of EIMs in Indian patients is comparable [78, 79]. In a study from our centre, the overall prevalence of any EIM and multiple EIMs in UC and CD was 33.2 versus $38.3 \%$ and 6.9 versus $4.7 \%$, respectively [80]. The prevalence of EIMs in Western studies has varied from 36 to $52 \%$ for UC and from 24 to $42 \%$ for CD, with the prevalence of multiple EIMs being reported as $6 \%[81,82]$. The prevalence of EIMs in Indian studies is higher than that reported in other Asian countries like Iran [83], China [64], South Korea [84], and Thailand [85]. The most common EIM reported in both UC and CD was periph-

Epidemiology of IBD in India eral arthropathy. Like in studies from the West, the frequency of EIMs correlated with disease severity in UC and disease location in $\mathrm{CD}$, with colonic disease having the highest frequency.

Unlike in the West [86] where the prevalence of primary sclerosing cholangitis (PSC) has been reported to vary from 2.4 to $7.4 \%$, the frequency of PSC in our study was only $0.4 \%$ in UC patients, and no CD patient was reported to have PSC. The frequency of PSC in UC patients from other Asian countries varied from 1.3 to $3.9 \%$ [77, 83]. The prevalence of PSC varies, owing to differences in definition or methods of diagnosis. The reason for such a low prevalence of PSC in India might be due to the overall low prevalence rate of autoimmune liver disease in Indian patients. Autoimmune liver disease accounted for only $1.7-5.7 \%$ of all cases of chronic liver disease in published reports from India [87, 88]. Among them, PSC accounted for only $5.2 \%$ of all autoimmune liver disease cases and $0.2 \%$ of all cases of chronic liver disease.

\section{Family History}

In general, the reports on family history in Indian IBD patients indicate that a positive family history is seen at a much lower frequency than in the West, where it has been reported to vary from 5 to $18 \%[89,90]$. The Indian IBD survey reported a positive family history in $2.3 \%$ of all UC patients [23], and we have recently reported a positive family history in $1.5 \%$ among 2,058 UC patients [91]. Similar to India, a positive family history is also seen at a lower frequency in other Asian countries like Sri Lanka (2.1\%) [92], Japan (2.7\%) [93], South Korea (2.01-6.5\%) $[94,95]$, and China (1.48\%) [64].

\section{Pregnancy and IBD}

Pregnancy and IBD have a complex interaction and can influence the natural history of each other. Like in the West, we documented that IBD affects pregnancy outcomes; there were more caesarean deliveries and a higher number of pre-term births and abortions in pregnancies that occurred after the diagnosis of IBD as compared to pregnancies without IBD [96]. These outcomes were worse in CD patients than in UC patients. We also demonstrated that pregnancy modifies the long-term course of IBD, and the disease course is worst when pregnancy coincides with disease onset. Secondly, as demonstrated in a multicentre European cohort [97] where the number of disease flares decreased after pregnancy, we also showed that the disease course of non-pregnant IBD patients was worse than that of pregnant IBD patients when pregnancy occurred before or after disease onset.

Inflamm Intest Dis 2017;2:102-115 DOI: $10.1159 / 000465522$ 


\section{Colorectal Cancer}

Because the risk of sporadic colorectal cancer (CRC) is much lower in India than in the West [98], the same was thought for the risk of CRC in UC patients. Earlier studies from India which assessed the risk of CRC in UC patients reported a much lower risk of CRC in Indian UC patients $[99,100]$. However, these were retrospective studies and included smaller study populations. Recent studies from Mumbai and our centre have reported risk rates which matched those of the West [101, 102]. Desai et al. [101] from Mumbai reported an incidence density of 3/1,000 in the first 10 years, 3.3/1,000 at 10-20 years, and 7/1,000 at $>20$ years with an overall prevalence of $2.8 \%$. We reported an annual incidence of $0.3 \%$, which is similar to rates reported in Western literature (0.3-3.3\%) with an overall prevalence of $1.9 \%$. The cumulative probability of developing CRC in our study was $1.5,7.2$, and $23.6 \%$ in the first, second, and third decade, respectively, which was similar to the meta-analysis by Eaden et al. [103] who reported the cumulative probability of developing CRC as 2,8 , and $18 \%$ in the first, second, and third decade, respectively (Fig. 5). In a recent meta-analysis on the risk of CRC in Asian studies, we found that in 44 studies, the overall prevalence was $0.85 \%$ and the cumulative probability of CRC at 10,20, and 30 years was $0.02,4.81$, and $13.91 \%$, respectively [104]. More so, the cumulative risk as reported in our study and the meta-analysis was much higher than that reported from population-based cohorts from the West which reported a probability of $0.6,5.4$, and $7.4 \%$ in the first, second, and third decade, respectively.

\section{Conclusion}

IBD can no longer be considered in its infancy in India; and with a staggering rise in both the disease burden and the population, India is projected to have amongst the highest numbers of IBD patients in the world. IBD affects individuals in their most productive years and is associated with a considerable morbidity and loss of functional capacity along with the burden of costly and prolonged treatment. IBD in India is as aggressive as in the West and requires a similar treatment approach. Challenges in treating IBD include the expense of therapy, the lack of medical insurance cover, and the poor acceptance of patients for surgery. With the rising disease burden, this geographical region provides an opportunity for elucidating possible aetiopathogenetic factors. Research should also focus on developing low-cost therapies which would not only help the patients in India but also in entire Asia, which like India is experiencing a rise in IBD disease burden along with scarce resources to tackle this problem.

\section{Disclosure Statement}

The authors declare that they have no conflicts of interest.

\section{Funding Sources}

The article did not receive any funding.

\section{References}

1 Ahuja V, Tandon RK: Inflammatory bowel disease: the Indian augury. Indian J Gastroenterol 2012;31:294-296.

2 Tandon BN, Mathur AK, Mohapatra LN, Tandon HD, Wig KL: A study of the prevalence and clinical pattern of non-specific ulcerative colitis in northern India. Gut 1965;6: 448-453.

3 Khosla SN, Girdhar NK, Lal S, Mishra DS: Epidemiology of ulcerative colitis in hospital and select general population of northern India. J Assoc Physicians India 1986;34:405-407.

4 Sood A, Midha V, Sood N, Bhatia AS, Avasthi G: Incidence and prevalence of ulcerative colitis in Punjab, North India. Gut 2003;52: $1587-1590$
5 Ng SC, Tang W, Ching JY, et al; Asia-Pacific Crohn's and Colitis Epidemiologic Study (ACCESS) Study Group: Incidence and phenotype of inflammatory bowel disease based on results from the Asia-pacific Crohn's and colitis epidemiology study. Gastroenterology 2013;145:158-165.

6 Al-Shamali MA, Kalaoui M, Patty I, Hasan F, Khajah A, Al-Nakib B: Ulcerative colitis in Kuwait: a review of 90 cases. Digestion 2003; 67:218-224.

7 Tezel A, Dökmeci G, Eskiocak M, Umit H, Soylu AR: Epidemiological features of ulcerative colitis in Trakya, Turkey. J Int Med Res 2003;31:141-148

8 Niv Y, Abuksis G, Fraser GM: Epidemiology of ulcerative colitis in Israel: a survey of Israeli kibbutz settlements. Am J Gastroenterol 2000;95:693-698.
9 Das K, Ghoshal UC, Dhali GK, Benjamin J, Ahuja V, Makharia GK: Crohn's disease in India: a multicenter study from a country where tuberculosis is endemic. Dig Dis Sci 2009;54: 1099-1107.

10 Hou JK, El-Serag H, Thirumurthi S: Distribution and manifestations of inflammatory bowel disease in Asians, Hispanics, and African Americans: a systematic review. Am J Gastroenterol 2009;104:2100-2109.

11 Yang SK, Loftus EV Jr, Sandborn WJ: Epidemiology of inflammatory bowel disease in Asia. Inflamm Bowel Dis 2001;7:260-270.

12 Thia KT, Loftus EV Jr, Sandborn WJ, Yang SK: An update on the epidemiology of inflammatory bowel disease in Asia. Am J Gastroenterol 2008;103:3167-3182. 
13 Abramson O, Durant M, Mow W, et al: Incidence, prevalence, and time trends of pediatric inflammatory bowel disease in Northern California, 1996-2006. J Pediatr 2010;157: 233-239.

14 Ahuja V, Tandon RK: Inflammatory bowel disease in the Asia-Pacific area: a comparison with developed countries and regional differences. J Dig Dis 2010;11:134-147.

15 Molodecky NA, Soon IS, Rabi DM, et al: Increasing incidence and prevalence of the inflammatory bowel diseases with time, based on systematic review. Gastroenterology 2012; 142:46-54.

16 Loftus EV Jr: Clinical epidemiology of inflammatory bowel disease: incidence, prevalence, and environmental influences. Gastroenterology 2004;126:1504-1517.

17 Loftus CG, Loftus EV Jr, Harmsen WS, Zinsmeister AR, Tremaine WJ, Melton LJ 3rd, Sandborn WJ: Update on the incidence and prevalence of Crohn's disease and ulcerative colitis in Olmsted County, Minnesota, 19402000. Inflamm Bowel Dis 2007;13:254-261.

18 Langholz E, Munkholm P, Nielsen OH, Kreiner S, Binder V: Incidence and prevalence of ulcerative colitis in Copenhagen county from 1962 to 1987 . Scand J Gastroenterol 1991;26:1247-1256.

19 Lok KH, Hung HG, Ng CH, et al: Epidemiology and clinical characteristics of ulcerative colitis in Chinese population: experience from a single center in Hong Kong. J Gastroenterol Hepatol 2008;23:406-410.

20 Sung JJ, Hsu RK, Chan FK, Liew CT, Lau JW, Li AK: Crohn's disease in the Chinese population. An experience from Hong Kong. Dis Colon Rectum 1994;37:1307-1309.

21 Shivananda S, Lennard-Jones J, Logan R, Fear N, Price A, Carpenter L, van Blankenstein M: Incidence of inflammatory bowel disease across Europe: is there a difference between north and south? Results of the European Collaborative Study on Inflammatory Bowel Disease (EC-IBD). Gut 1996;39:690-697.

22 Khalili H, Huang ES, Ananthakrishnan AN, et al: Geographical variation and incidence of inflammatory bowel disease among US women. Gut 2012;61:1686-1692.

23 Makharia GK, Ramakrishna BS, Abraham P, et al; Indian Society of Gastroenterology Task Force on Inflammatory Bowel Disease: Survey of inflammatory bowel diseases in India. Indian J Gastroenterol 2012;31:299-306.

24 Nerich V, Jantchou P, Boutron-Ruault MC, et al: Low exposure to sunlight is a risk factor for Crohn's disease. Aliment Pharmacol Ther 2011;33:940-945.

25 Chouraki V, Savoye G, Dauchet L, et al: The changing pattern of Crohn's disease incidence in northern France: a continuing increase in the 10- to 19-year-old age bracket (1988-2007). Aliment Pharmacol Ther 2011; 33:1133-1142.

26 Yang SK, Yun S, Kim JH, et al: Epidemiology of inflammatory bowel disease in the SongpaKangdong district, Seoul, Korea, 1986-2005: a KASID study. Inflamm Bowel Dis 2008;14: 542-549.

27 Thia KT, Luman W, Jin OC: Crohn's disease runs a more aggressive course in young Asian patients. Inflamm Bowel Dis 2006;12:57-61.

28 Tsironi E, Feakins RM, Probert CS, Rampton DS, Phil D: Incidence of inflammatory bowel disease is rising and abdominal tuberculosis is falling in Bangladeshis in East London, United Kingdom. Am J Gastroenterol 2004;99: 1749-1755.

29 Singh P, Ananthakrishnan A, Ahuja V: Pivot to Asia: inflammatory bowel disease burden. Intest Res 2017;15:138-141.

30 Probert CS, Jayanthi V, Pinder D, Wicks AC, Mayberry JF: Epidemiological study of ulcerative proctocolitis in Indian migrants and the indigenous population of Leicestershire. Gut 1992;33:687-693.

31 Jayanthi V, Probert CS, Pinder D, Wicks AC, Mayberry JF: Epidemiology of Crohn's disease in Indian migrants and the indigenous population in Leicestershire. Q J Med 1992; 82:125-138.

32 Benchimol EI, Mack DR, Guttmann A, et al: Inflammatory bowel disease in immigrants to Canada and their children: a populationbased cohort study. Am J Gastroenterol 2015; 110:553-563.

33 Jostins L, Ripke S, Weersma RK, et al: International IBD Genetics Consortium (IIBDGC), Silverberg MS, Annese V, Hakonarson H, Brant SR, Radford-Smith G, Mathew CG, Rioux JD, Schadt EE, Daly MJ, Franke A, Parkes M, Vermeire S, Barrett JC, Cho JH: Host-microbe interactions have shaped the genetic architecture of inflammatory bowel disease. Nature 2012;491:119-124.

$34 \mathrm{Liu}$ JZ, van Sommeren S, Huang H, et al: Association analyses identify 38 susceptibility loci for inflammatory bowel disease and highlight shared genetic risk across populations. Nat Genet 2015;47:979-986.

35 Pugazhendhi S, Amte A, Balamurugan R, Subramanian V, Ramakrishna BS: Common NOD2 mutations are absent in patients with Crohn's disease in India. Indian J Gastroenterol 2008;27:201-203.

36 Mahurkar S, Banerjee R, Rani VS, et al: Common variants in NOD2 and IL23R are not associated with inflammatory bowel disease in Indians. J Gastroenterol Hepatol 2011;26: 694-699.

37 Pugazhendhi S, Santhanam S, Venkataraman J, Creveaux I, Ramakrishna BS: NOD2 gene mutations associate weakly with ulcerative colitis but not with Crohn's disease in Indian patients with inflammatory bowel disease. Gene 2013;512:309-313.

38 Juyal G, Prasad P, Senapati S, Midha V, Sood A, Amre D, Juyal RC, BK T: An investigation of genome-wide studies reported susceptibility loci for ulcerative colitis shows limited replication in north Indians. PLoS One 2011; 6:e16565.

39 Baskaran K, Pugazhendhi S, Ramakrishna BS: Protective association of tumor necrosis fac- tor superfamily 15 (TNFSF15) polymorphic haplotype with Ulcerative Colitis and Crohn's disease in an Indian population. PLoS One 2014;9:e114665.

40 Yamazaki K, McGovern D, Ragoussis J, et al: Single nucleotide polymorphisms in TNFSF 15 confer susceptibility to Crohn's disease. Hum Mol Genet 2005;14:3499-3506.

41 Thiébaut R, Kotti S, Jung C, et al: TNFSF15 polymorphisms are associated with susceptibility to inflammatory bowel disease in a new European cohort. Am J Gastroenterol 2009; 104:384-391.

42 Baskaran K, Pugazhendhi S, Ramakrishna BS: Association of IRGM gene mutations with inflammatory bowel disease in the Indian population. PLoS One 2014;9:e106863.

43 Verma R, Ahuja V, Paul J: Detection of singlenucleotide polymorphisms in the intron 9 region of the nucleotide oligomerization domain-1 gene in ulcerative colitis patients of North India. J Gastroenterol Hepatol 2012;27: 96-103.

44 Verma R, Ahuja V, Paul J: Frequency of single nucleotide polymorphisms in NOD1 gene of ulcerative colitis patients: a case-control study in the Indian population. BMC Med Genet 2009; 10:82.

45 Meena NK, Verma R, Verma N, Ahuja V, Paul J: TLR4 D299G polymorphism modulates cytokine expression in ulcerative colitis. J Clin Gastroenterol 2013;47:773-780.

46 Meena NK, Ahuja V, Meena K, Paul J: Association of TLR5 gene polymorphisms in ulcerative colitis patients of north India and their role in cytokine homeostasis. PLoS One 2015;10:e120697.

47 Juyal G, Midha V, Amre D, Sood A, Seidman E, Thelma BK: Associations between common variants in the MDR1 (ABCB1) gene and ulcerative colitis among North Indians. Pharmacogenet Genomics 2009;19:77-85.

48 Ahirwar DK, Kesarwani P, Singh R, Ghoshal UC, Mittal RD: Role of tumor necrosis factoralpha (C-863A) polymorphism in pathogenesis of inflammatory bowel disease in Northern India. J Gastrointest Cancer 2012;43:196-204.

49 Juyal G, Negi S, Sood A, et al: Genome-wide association scan in north Indians reveals three novel HLA-independent risk loci for ulcerative colitis. Gut 2015;64:571-579.

50 Tosa M, Negoro K, Kinouchi Y, et al: Lack of association between IBD5 and Crohn's disease in Japanese patients demonstrates populationspecific differences in inflammatory bowel disease. Scand J Gastroenterol 2006;41:48-53.

51 Yamazaki K, Takazoe M, Tanaka T, Kazumori T, Nakamura Y: Absence of mutation in the NOD2/CARD15 gene among 483 Japanese patients with Crohn's disease. J Hum Genet 2002;47:469-472.

52 Strober W, Fuss I, Mannon P: The fundamental basis of inflammatory bowel disease. J Clin Invest 2007;117:514-521.

53 Sheehan D, Moran C, Shanahan F: The microbiota in inflammatory bowel disease. J Gastroenterol 2015;50:495-507. 
54 Verma R, Verma AK, Ahuja V, Paul J: Realtime analysis of mucosal flora in patients with inflammatory bowel disease in India. J Clin Microbiol 2010;48:4279-4282.

55 Conte MP, Schippa S, Zamboni I, et al: Gutassociated bacterial microbiota in paediatric patients with inflammatory bowel disease. Gut 2006;55:1760-1767.

56 Ott SJ, Plamondon S, Hart A, et al: Dynamics of the mucosa-associated flora in ulcerative colitis patients during remission and clinical relapse. J Clin Microbiol 2008;46:3510-3513.

57 Zhang M, Liu B, Zhang Y, Wei H, Lei Y, Zhao L: Structural shifts of mucosa-associated lactobacilli and Clostridium leptum subgroup in patients with ulcerative colitis. J Clin Microbiol 2007;45:496-500.

58 Andoh A, Imaeda H, Aomatsu T, et al: Comparison of the fecal microbiota profiles between ulcerative colitis and Crohn's disease using terminal restriction fragment length polymorphism analysis. J Gastroenterol 2011; 46:479-486.

59 van der Wiel-Korstanje JA, Winkler KC: The faecal flora in ulcerative colitis. J Med Microbiol 1975;8:491-501.

60 Kumari R, Ahuja V, Paul J: Fluctuations in butyrate-producing bacteria in ulcerative colitis patients of North India. World J Gastroenterol 2013;19:3404-3414.

61 Sokol H, Seksik P, Rigottier-Gois L, et al: Specificities of the fecal microbiota in inflammatory bowel disease. Inflamm Bowel Dis 2006;12:106-111.

62 To N, Gracie DJ, Ford AC: The importance of smoking cessation in improving disease course in Crohn's disease. Am J Gastroenterol 2016;111:1198.

63 Quezada SM, Langenberg P, Cross RK: Cigarette smoking adversely affects disease activity and disease-specific quality of life in patients with Crohn's disease at a tertiary referral center. Clin Exp Gastroenterol 2016;9: 307-310.

64 Jiang XL, Cui HF: An analysis of 10218 ulcerative colitis cases in China. World J Gastroenterol 2002;8:158-161.

65 Pugazhendhi S, Sahu MK, Subramanian V, Pulimood A, Ramakrishna BS: Environmental factors associated with Crohn's disease in India. Indian J Gastroenterol 2011;30:264269.

66 Sood A, Amre D, Midha V, et al: Low hygiene and exposure to infections may be associated with increased risk for ulcerative colitis in a North Indian population. Ann Gastroenterol 2014;27:219-223.

67 Ng SC, Tang W, Leong RW, et al; Asia-Pacific Crohn's and Colitis Epidemiology Study ACCESS Group: Environmental risk factors in inflammatory bowel disease: a populationbased case-control study in Asia-Pacific. Gut 2015;64:1063-1071.
68 Kalaria R, Desai D, Abraham P, Joshi A, Gupta $\mathrm{T}$, Shah S: Temporal change in phenotypic behaviour in patients with Crohn's disease: do Indian patients behave differently from Western and other Asian patients? J Crohns Colitis 2016;10:255-261.

69 Rai T, Choudhury BN, Kedia S, Bopanna S, Venigalla PM, Garg SK, Singla V, Makharia G, Ahuja V: Short-term clinical response to corticosteroids can predict long-term natural history of ulcerative colitis: prospective study experience. Dig Dis Sci 2017;62:1025-1034.

70 Dinesen LC, Walsh AJ, Protic MN, et al: The pattern and outcome of acute severe colitis. J. Crohns Colitis 2010;4:431-437.

71 Jain S, Kedia S, Sethi T, et al: Long-term outcome after acute severe ulcerative colitis in India. Indian J Gastroenterol 2016;35(suppl 1):A1-A111.

72 Gustavsson A, Halfvarson J, Magnuson A, et al: Long-term colectomy rate after intensive intravenous corticosteroid therapy for ulcerative colitis prior to the immunosuppressive treatment era. Am J Gastroenterol 2007;102: 2513-2519.

73 Bojic D, Radojicic Z, Nedeljkovic-Protic M, et al: Long-term outcome after admission for acute severe ulcerative colitis in Oxford: the 1992-1993 cohort. Inflamm Bowel Dis 2009; 15:823-828.

74 Molnár T, Farkas K, Nyári T, et al: Response to first intravenous steroid therapy determines the subsequent risk of colectomy in ulcerative colitis patients. J. Gastrointest Liver Dis JGLD 2011;20:359-363.

75 Lee H-S, Yang S-K, Soh JS, et al: Short- and long-term outcomes of acute severe ulcerative colitis in Korea: the 1999-2005 cohort. Inflamm Bowel Dis 2015;21:1825-1831.

76 Pratap Mouli V, Munot K, Ananthakrishnan A, et al: Endoscopic and clinical responses to anti-tubercular therapy can differentiate intestinal tuberculosis from Crohn's disease. Aliment Pharmacol Ther 2017;45:27-36.

77 Pokharna RK, Kabra PK, Sharma R, Kochar DK: Extraintestinal manifestations of idiopathic ulcerative colitis in northwestern India. Indian J Gastroenterol 2004;23:89-90.

78 Kochhar R, Mehta SK, Nagi B, Bhatia V, Goenka MK, Malik AK: Extraintestinal manifestations of idiopathic ulcerative colitis. Indian J Gastroenterol 1991;10:88-89.

79 Bandyopadhyay D, Bandyopadhyay S, Ghosh $\mathrm{P}$, et al: Extraintestinal manifestations in inflammatory bowel disease: prevalence and predictors in Indian patients. Indian J Gastroenterol 2015;34:387-394.

80 Singh B, Kedia S, Konijeti G, et al: Extraintestinal manifestations of inflammatory bowel disease and intestinal tuberculosis: frequency and relation with disease phenotype. Indian J Gastroenterol 2015;34:43-50.

81 Greenstein AJ, Janowitz HD, Sachar DB: The extra-intestinal complications of Crohn's disease and ulcerative colitis: a study of 700 patients. Medicine (Baltimore) 1976;55:401-412.
82 Mendoza JL, Lana R, Taxonera C, Alba C, Izquierdo S, Díaz-Rubio M: Extraintestinal manifestations in inflammatory bowel disease: differences between Crohn's disease and ulcerative colitis (in Spanish). Med Clin (Barc) 2005;125:297-300.

83 Aghazadeh R, Zali MR, Bahari A, Amin K, Ghahghaie F, Firouzi F: Inflammatory bowel disease in Iran: a review of 457 cases. J Gastroenterol Hepatol 2005;20:1691-1695.

84 Kim ES, Kim WH: Inflammatory bowel disease in Korea: epidemiological, genomic, clinical, and therapeutic characteristics. Gut Liver 2010;4:1-14.

85 Pongprasobchai S, Manatsathit S, Leelakusolvong S, Sattawatthamrong Y, Boonyapisit S: Ulcerative colitis in Thailand: a clinical study and long term follow-up. J Med Assoc Thai 2001;84:1281-1288.

86 Rasmussen $\mathrm{HH}$, Fallingborg J, Mortensen PB, Freund L, Tage-Jensen U, Kruse V, Rasmussen SN: Primary sclerosing cholangitis in patients with ulcerative colitis. Scand J Gastroenterol 1992;27:732-736.

87 Amarapurkar DN, Patel ND: Spectrum of autoimmune liver diseases in western India. J Gastroenterol Hepatol 2007;22:2112-2117.

88 Gupta R, Agarwal SR, Jain M, Malhotra V, Sarin SK: Autoimmune hepatitis in the Indian subcontinent: 7 years experience. J Gastroenterol Hepatol 2001;16:1144-1148.

89 Monsén U, Broström O, Nordenvall B, Sörstad J, Hellers G: Prevalence of inflammatory bowel disease among relatives of patients with ulcerative colitis. Scand J Gastroenterol 1987;22:214-218.

90 Yang H, McElree C, Roth MP, Shanahan F, Targan SR, Rotter JI: Familial empirical risks for inflammatory bowel disease: differences between Jews and non-Jews. Gut 1993;34: 517-524.

91 Gupta A, Bopanna A, Kedia S, et al: Familial aggregation of inflammatory bowel disease in patients of ulcerative colitis. Intes Res (abstract).

92 Niriella MA, De Silva AP, Dayaratne AH, et al: Prevalence of inflammatory bowel disease in two districts of Sri Lanka: a hospital based survey. BMC Gastroenterol 2010;10:32.

93 Kuwahara E, Asakura K, Nishiwaki Y, et al: Effects of family history on inflammatory bowel disease characteristics in Japanese patients. J Gastroenterol 2012;47:961-968.

94 Chung SH, Park SJ, Lee HS, et al: Similar clinical characteristics of familial and sporadic inflammatory bowel disease in South Korea. World J Gastroenterol 2014;20:17120-17126.

95 Hwang SW, Kwak MS, Kim WS, et al: Influence of a positive family history on the clinical course of inflammatory bowel disease. J Crohns Colitis 2016;10:1024-1032.

96 Padhan RK, Kedia S, Garg SK, et al: Longterm disease course and pregnancy outcomes in women with inflammatory bowel disease: an Indian cohort study. Dig Dis Sci 2016, Epub ahead of print. 
97 Riis L, Vind I, Politi P, et al; European Collaborative study group on Inflammatory Bowel Disease: Does pregnancy change the disease course? A study in a European cohort of patients with inflammatory bowel disease. Am J Gastroenterol 2006;101:1539-1545.

98 Ferlay J, Shin HR, Bray F, et al: Estimates of worldwide burden of cancer in 2008: GLOBOCAN 2008. Int J Cancer 2010;127:28932917.

99 Kochhar R, Goenka MK, Kaushik SP, et al: Colorectal carcinoma in Indian patients with idiopathic ulcerative colitis. Eur J Cancer Prev 1992;1:293-296.
100 Venkataraman S, Mohan V, Ramakrishna B, et al: Risk of colorectal cancer in ulcerative colitis in India. J Gastroenterol Hepatol 2005;20:705-709.

101 Desai D, Shah S, Deshmukh A, et al: Colorectal cancers in ulcerative colitis from a lowprevalence area for colon cancer. World J Gastroenterol 2015;21:3644-3649.
102 Bopanna S, Kedia S, Das P, et al: Long-term follow-up reveals high incidence of colorectal cancer in Indian patients with inflammatory bowel disease. United European Gastroenterol J 2016, DOI: 10.1177/ 2050640616680552.

103 Eaden JA, Abrams KR, Mayberry JF: The risk of colorectal cancer in ulcerative colitis: a meta-analysis. Gut 2001;48:526-535.

104 Bopanna S, Ananthakrishnan A, Kedia S, Yajnik V, Ahuja V: Risk of colorectal cancer in Asian patients with ulcerative colitis: a systematic review and meta-analysis. Lancet Gastroenterol Hepatol 2017;2:269-276. 